\title{
Psychometric properties of Health Literacy in Dentistry scale in an elderly Brazilian population
}

\author{
Fábio Luiz MIALHE(a) \\ Carla Fabiana TENANI(a) iD \\ Maria Helena Ribeiro \\ DE CHECCHI(a) ID \\ Lisa JAMIESON ${ }^{(b)}$ iD \\ Xiangqun $\mathrm{JU}^{(\mathbf{b})}$ iD \\ (a) Universidade Estadual de Campinas \\ - Unicamp, Piracicaba Dental School, \\ Department of Health Science and Pediatric \\ Dentistry, Piracicaba, SP, Brazil. \\ (b) University of Adelaide, Adelaide Dental \\ School, Australian Research Centre for \\ Population Oral Health, Adelaide, South \\ Australia, Australia.
}

Declaration of Interests: The authors certify that they have no commercial or associative interest that represents a conflict of interest in connection with the manuscript.

\section{Corresponding Author:}

Fábio Luiz Mialhe

E-mail:mialhe@unicamp.br

https://doi.org/10.1590/1807-3107bor-2020.vol34.0021

Submitted: September 4, 2019

Accepted for publication: December 27, 2019

Last revision: Janurary 16, 2020

\begin{abstract}
This study aimed to assess the reliability and validity of Brazilian-Portuguese versions of the Health Literacy in Dentistry (HeLD) scale in a sample of elderly Brazilian participants. HeLD was initially translated into and cross-culturally adapted to the Brazilian Portuguese language. The reliability and validity of HeLD were then assessed in a sample of 535 non-institutionalized older persons who also completed a questionnaire containing sociodemographic and health information. Data were then randomly separated into two sub-datasets, and Confirmatory Factor Analysis was performed through structural equation modelling, with a maximum likelihood estimate to test the fit of the data to the factor structure of the long-and short-form HeLD (HeLD-29 and HeLD-14) versions of the instrument. The models were compared using the Akaike Information Criterion to assess goodness-of-fit and to determine which models were preferred. Internal consistency of HeLD was evaluated using Cronbach's coefficient $\alpha$. Both versions of HeLD were observed to demonstrate high internal reliability (Cronbach's $\alpha \geq 0.87$ for all seven subscales), acceptable convergent (estimates of $\geq 0.50$ for AVE and $\geq 0.70$ for CR) and discriminant validity. However, the goodness-of-fit of the confirmatory factor analysis models demonstrated satisfactory results only for HeLD14 subsamples $(\mathrm{x} 2 / \mathrm{df}=1.8-2.3 ; \mathrm{CFI}=0.97-0.98$; GFI $/ \mathrm{NFI}=0.98-0.99$; RMSEA $=0.05$ and SRMR $=0.03$ ). In conclusion, HeLD-14 was shown to be a reliable and valid instrument to measure oral health literacy in elderly Brazilian participants.
\end{abstract}

Keywords: Oral Health; Health Literacy; Psychometrics; Aged.

\section{Introduction}

Health literacy (HL) is an established construct in public health, with studies demonstrating associations between this construct and health outcomes. ${ }^{1,2}$ It was defined by Nutbeam ${ }^{3}$ as "personal, cognitive and social skills which determine the ability of individuals to gain access to, understand, and use information to promote and maintain good health". According to the European Health Literacy Consortium, HL "is linked to literacy and entails people's knowledge, motivation and competences to access, understand, appraise and apply health information in order to make judgements and take decisions in everyday life concerning health care, 
disease prevention and health promotion to maintain or improve quality of life during the life course".2 Therefore, HL is considered an important determinant of health, especially in vulnerable populations such as immigrants, the homeless and elderly. ${ }^{2}$

Nutbeam ${ }^{3}$ conceptualizes HL in three levels, based on types of literacy: a) Basic/functional, which is related to "basic skills in reading and writing to be able to function effectively in everyday situations"; b) Communicative / interactive, which is related to "more advanced cognitive and literacy skills which, together with social skills, can be used to actively participate in everyday activities, to extract information and derive meaning from different forms of communication, and to apply new information to changing circumstances" and c) Critical, which is related to "more advanced cognitive skills which, together with social skills, can be applied to critically analyses information, and to use this information to exert greater control over life events and situations". In dentistry, the majority of studies in the field of oral health literacy (OHL) have used instruments based on word recognition such as REALD- $30^{4,5}$ which only address the first aspect of HL described by Nutbeam. ${ }^{3}$

In Brazil, there are so far three instruments that measure OHL that have been adequately validated through robust psychometric analysis for the Brazilian population, namely: the Brazilian version of The Rapid Estimate of Adult Literacy in Dentistry (BREALD-30); the Brazilian version of the 20 -item rapid estimate of adult literacy in medicine and dentistry ${ }^{7}$ and recently, the Brazilian version of the Oral Health Literacy Assessment in Spanish. ${ }^{8}$ All instruments measure aspects of OHL by using word recognition tests and were tested in samples of predominantly adult individuals.

Therefore, taking into account the definition of OHL by the American Dental Association "the degree to which individuals have the capacity to obtain, process and understand basic health information and services needed to make appropriate oral health decisions", ${ }^{\prime \prime}$ it is important for future studies to investigate OHL levels and their association with dental outcomes using tools that measure a broader scope of the construct, such as the Health Literacy in Dentistry (HeLD) scale. HeLD is a comprehensive OHL assessment tool developed and validated with
Australian adults that is theoretically underpinned by seven conceptual domains related to OHL. 10,11,12 To date, there are only three studies published with the instrument in populations outside Australia, one in USA with adults ${ }^{13}$ and two in Indonesia with adolescents. ${ }^{14,15}$ In addition, none of the studies published have evaluated its psychometric properties in elderly populations even with the large body of evidence has shown that people over the age of 60 are the fastest growing population and will reach nearly 2.1 billion habitants worldwide by $2050 .{ }^{16}$ This fact poses a number of challenges to health professionals and health systems because older people experience a greater number of health disorders, including oral health. ${ }^{16,17}$ Epidemiological surveys have shown that a large proportion of older people worldwide present poor oral heath demonstrated by evidence of high levels of dental caries experience and tooth loss, periodontal disease, xerostomia and oral cancer. ${ }^{18,19,20}$ In Brazil, the older population has higher levels of caries experience (mean decayed, missing and filled teeth index $=27.5$ ), with over half being edentulous. ${ }^{21}$

In spite of compelling evidence that general HL is strongly associated with health outcomes in older persons, ${ }^{22,23}$ in the field of dentistry there are few publications investigating associations between $\mathrm{OHL}$ and oral health outcomes in this population. ${ }^{24,25,26}$

Taking into consideration these aspects and the demand for validated instruments measuring $\mathrm{OHL}$ in the elderly, the aim of present study was to assess the reliability and validity of the long and short version of the Health Literacy in Dentistry instrument in an elderly Brazilian population.

\section{Methodology}

The protocol of this study was reviewed and approved by an Ethics Committee and in accordance with the Declaration of Helsinki ethical principles for medical research involving human subjects. All participants provided written informed consent. This was a cross-sectional study conducted with non-institutionalized older people living in the city of Piracicaba, with an estimated population of 400,000 inhabitants, located in the southeast region of Brazil and $160 \mathrm{~km}$ from the capital São Paulo. 


\section{Health literacy in Dentistry (HeLD)}

Health Literacy in Dentistry (HeLD) scale comprises a long (HeLD-29) and short form (HeLD-14). Both forms represent 7 conceptual domains: access, understanding, support, utilization, economic barriers, receptivity and communication. Each item is scored using 5-point ordinal items ranging from 0 ('Unable to do') to 4 ('without any difficulty'). The possible range of summary scores is from 0-116 (HeLD-29) and 0-56 (HeLD-14). Higher scores indicate higher oral health literacy levels. ${ }^{10,11,12}$

\section{Questionnaire translation and cross-cultural adaptation}

Initially the instrument was translated into and cross culturally adapted to the Brazilian Portuguese language according to the protocol suggested by Guillemin et al. ${ }^{27}$ Firstly, an initial translation of the instrument was done by two independent translators, then back translation by two independent native English language translators who had no access to the original instrument, and then reviewed by a committee of experts and a pretest. The review committee consisted of four dental researchers with translation experience and knowledge of oral health literacy, a Brazilian-Portuguese teacher and a linguistic researcher. The review committee evaluated all stages of the process, the original and the final versions of the instrument, and by consensus, chose the best words for adapting them to the Brazilian population. In addition, contacts were made with the authors of the instrument for clarification and better translations of the meaning of the questions. ${ }^{27}$ In order to evaluate the instructions, response format and items of the instrument for clarity (cross cultural adaptation process), the pre-final version of the instrument was pilot-tested with a convenience sample of 25 elderly persons with a mean age of 68.5 years, with diverse levels of schooling. A cognitive interview was held to test if the meaning of the items was equivalent to those of the original source. The results of the cultural adaptation showed that the Brazilian version of HeLD-29 was well understood by the sample and the level of misunderstanding did not exceed $20 \%$ in any of the questions, as recommended in cross-cultural adaptation of instruments for health care research. ${ }^{28}$

\section{Data collection and participants}

In order to investigate the psychometric properties of the translated version of HeLD the instrument was administered to 535 older individuals aged 60 years and older who were living independently and were generally healthy without remarkable cognitive alteration. The presence or not of cognitive impairment was evaluated by the medical records of the elders which were collected in the Family Health Units with whom participants were registered. The sample size calculation in psychometric studies is usually done on the number of items and Hair et al. ${ }^{29}$ recommends that the proportion of 5 respondents for each item of the instrument is the minimum acceptable to avoid errors due to sample size and the more acceptable sample size would have a 10:1 ratio. So the number of 535 subjects was considered sufficient for this rule considering that the original HeLD presents 29 items and data was later subdivided into two sub-datasets of approximately 270 individuals for statistical analysis enabled a ratio of 1:9, above the acceptable minimum.

Of these, 480 (89.7\%) lived close to 6 Family Health Units, and were selected by means of a simple random sampling process carried out after the researchers had consulted the primary health care information system, and chosen individuals who fulfilled all the inclusion criteria. In addition, another sample data were collected from 55 older adults randomly selected in the waiting rooms of a Dental Specialty Center (DCS) that receives older patients referred by the primary care teams from across the city. There were no statistically significant differences in sociodemographic variables between the two subsamples ( $p>0.05$ ). All data were obtained by means of an interviewer-administered questionnaire with the participation of two trained researchers.

In addition to the Brazilian version of HeLD, each participant completed a questionnaire containing sociodemographic and health variables, self-efficacy in tooth brushing at night and the Brazilian version of Geriatric Oral Health Assessment Index (GOHAI).

The sociodemographic characteristics included sex ('Male' or 'Female'), age (65 years or less' or 'Over 65 years), ethnicity ('White/yellow' or 'Others: indigenous, black'), marital status ('Married/cohabiting' or 'Single/divorced/widower'), highest education 
level (' 5 th grade or above' or 'Less than $5^{\text {th }}$ grade), and income ('Higher: $\geq \mathrm{R} \$ 1,875^{\prime}$ or 'Lower: $<\mathrm{R} \$ 1,875^{\prime}$ ). Health status included: self-rated general health dichotomized into 'excellent/very good/good' or 'Fair or poor', and health problems were 'None' or 'Had: Hypertension/Diabetes/ Hypertension and Diabetes/ Heart problems and others'. Satisfaction with oral health was measured using the following question: "With regard to your teeth/mouth, are you 'very satisfied', 'satisfied', 'neither satisfied nor dissatisfied', 'dissatisfied' or 'very dissatisfied?' and was dichotomized into 'Satisfied: very satisfied/Satisfied' or 'Unsatisfied: neither satisfied nor dissatisfied/ unsatisfied/ Very unsatisfied'. Oral health-related behaviors included: usual reason for dental visit ('check-up/repair/ maintenance' or 'problem').

Self-efficacy of individuals to brush their teeth at night was investigated by an instrument previously validated to Brazilian population. ${ }^{30}$

The oral health-related quality of life of the sample was measured by Geriatric Oral Health Assessment Index (GOHAI). ${ }^{31,32}$ In this study we used the simplified frequency range suggested by the authors with 3 categories and following values: 1- always; 2- sometimes and 3-never. In order to obtain the final index the sum of values was calculated, which ranged from 12-36. The highest value indicated values of high self-perception regarding oral health. Total GOHAI scores were dichotomized by the median of the sample into ' 30 or more' or 'Less than 30 '.

\section{Evaluation of the psychometric properties of the Brazilian version of HeLD}

We estimated central tendency, variability and shape of the distribution for each HeLD item in the older population. According to the literature, no severe deviations from normality are found if the absolute values of Kurtosis and Skewness are $<3.33,34,35$

For testing the validity and reliability of Held -29 and HeLD-14 in the different population, data was randomly split into two sub-datasets: sample size of 267 and 268, respectively. Confirmatory Factor Analysis (CFA) with the function of 'Proccalis' was performed through structural equation modelling, with the use of maximum likelihood estimate to test the fit of the data to the factor structure of both HeLD instruments.
Goodness-of-fit was assessed by using the chi-square $\left(x^{2}\right)$ and degrees of freedom ( $\left.d f\right)$ tests, Comparative Fit Index (CFI), Normed Fit Index (NFI), Goodness of Fit Index (GFI), Root Mean Square Error of Approximation (RMSEA), and Standardized Root MeanSquare Residual (SRMR). The following parameters were established as minimum indices for the adequacy of the model: $x^{2} / d f \leq 2.0, \mathrm{CFI}>0.95, \mathrm{GFI} / \mathrm{NFI}>0.90, \mathrm{RMSEA}<0.06$ and SRMR $<0.06 .{ }^{36,37}$ Models of the two instruments were compared using the Akaike Information Criterion (AIC) to evaluate goodness-of-fit and to determine which models should be selected. The lower the values of AIC, the better the model adjustment.

The degree of inter-relation for the items of each factor was measured through convergent validity and was estimated by calculating the average variance extracted (AVE) and composite reliability (CR). Strong inter-relation of items were considered when AVE $\geq 0.50$ and $C R \geq 0.70$. In order to assess whether the items of one factor were not more strongly correlated with another factor, discriminant validity was calculated. Parameters of adequate discriminant validity were considered when $A V E_{\mathrm{i}}$ and $A V E_{\mathrm{j}}$ were greater than the square of the correlation $\left(\rho_{\mathrm{ij}}{ }^{2}\right)$ between the factors $i$ and $j .{ }^{38}$

In relation to the internal consistency of models, they were considered to be acceptable when Cronbach standardized alpha $(\alpha)$ was $\geq 0.7$. The Student's- $t$ test was used to analyze the association between oral health literacy and oral health-related covariates by estimating the means and standard error for HeLD and each domain. Two-sided where available, $p$-value of 0.05 was considered statistically significance. Second-order models were developed for the models that presented adequate fit.

All data analysis was performed using SAS statistical software.

\section{Results}

Table 1 presents the summary for each HeLD 29 item, and total HeLD-29 and HeLD-14 scores.

It was observed that the kurtosis and skewness values indicated an approximation to a normal distribution, meaning each item satisfactorily met the required thresholds for assumptions of normality of the data. 
Table 1. Summary measures of each item of the Health Literacy in Dentistry scale (HeLD-29 and HeLD-14).

\begin{tabular}{|c|c|c|c|c|c|c|}
\hline Item & & Mean & SD & Median & Kurtoses & Skewness \\
\hline R1 & 1 & 3.1 & 1.2 & 4.0 & 0.3 & -1.1 \\
\hline R2 & 2 & 3.0 & 1.2 & 3.0 & 0.1 & -1.1 \\
\hline R3 & 3 & 3.2 & 1.1 & 4.0 & 1.0 & -1.3 \\
\hline R4 & 4 & 2.9 & 1.3 & 3.0 & -0.2 & -0.9 \\
\hline R5 & 5 & 2.7 & 1.4 & 3.0 & -0.9 & -0.7 \\
\hline U6 & 6 & 2.6 & 1.5 & 3.0 & -1.1 & -0.6 \\
\hline U7 & 7 & 2.8 & 1.4 & 3.0 & -0.7 & -0.8 \\
\hline U8 & 8 & 2.8 & 1.4 & 3.0 & -0.8 & -0.8 \\
\hline $\mathrm{X} 1$ & 9 & 2.3 & 1.6 & 3.0 & -1.5 & -0.4 \\
\hline S1 & 10 & 3.3 & 1.1 & 4.0 & 2.0 & -1.7 \\
\hline S2 & 11 & 3.3 & 1.1 & 4.0 & 2.4 & -1.8 \\
\hline S3 & 12 & 3.3 & 1.1 & 4.0 & 1.9 & -1.7 \\
\hline F1 & 13 & 1.5 & 1.5 & 1.0 & -1.2 & 0.4 \\
\hline F2 & 14 & 2.9 & 1.4 & 4.0 & -0.5 & -0.9 \\
\hline F3 & 15 & 2.0 & 1.4 & 2.0 & -1.4 & 0.0 \\
\hline $\mathrm{Al}$ & 16 & 3.4 & 1.1 & 4.0 & 1.8 & -1.6 \\
\hline A2 & 17 & 3.3 & 1.1 & 4.0 & 1.9 & -1.6 \\
\hline A3 & 18 & 3.2 & 1.2 & 4.0 & 1.1 & -1.5 \\
\hline A4 & 19 & 3.3 & 1.0 & 4.0 & 1.0 & -1.5 \\
\hline $\mathrm{Cl}$ & 20 & 3.0 & 1.5 & 4.0 & -0.1 & -1.0 \\
\hline $\mathrm{C} 2$ & 21 & 2.8 & 1.4 & 3.0 & -0.7 & -0.8 \\
\hline C3 & 22 & 2.7 & 1.4 & 3.0 & -0.9 & -0.7 \\
\hline $\mathrm{C} 4$ & 23 & 2.8 & 1.4 & 4.0 & -0.7 & -0.8 \\
\hline C5 & 24 & 2.7 & 1.5 & 3.0 & -0.9 & -0.7 \\
\hline $\mathrm{C} 6$ & 25 & 2.7 & 1.5 & 3.0 & -0.9 & -0.7 \\
\hline C7 & 26 & 3.0 & 1.2 & 3.0 & -0.1 & -0.9 \\
\hline X2 & 27 & 3.2 & 1.2 & 4.0 & -0.1 & -1.0 \\
\hline $\mathrm{X} 3$ & 28 & 3.0 & 1.2 & 3.0 & -0.1 & -1.0 \\
\hline $\mathrm{X} 4$ & 29 & 3.0 & 1.2 & 3.0 & -0.2 & -0.9 \\
\hline \multicolumn{2}{|c|}{ HeLD-29 } & 83.9 & 24.0 & 87.0 & 0.0 & -0.7 \\
\hline \multicolumn{2}{|c|}{ HeLD-14 } & 40.3 & 11.5 & 42.0 & 0.2 & -0.7 \\
\hline
\end{tabular}

Items in bold pertain to HeLD-14 items.
Table 2 shows the goodness-of- fit of the HeLD-29 and HeLD-14 confirmatory factor analysis models for the data I and data II, respectively.

The goodness-of-fit of the HeLD-29 confirmatory factor analysis models was observed to be poor for the two sub-samples. On the other hand, satisfactory goodness of fit was demonstrated for the two sub-samples using HeLD-14, with acceptable thresholds for CFI, GFI, NFI obtained. In addition, the models (HeLD-29 and HeLD-14) were compared using the Akaike Information Criterion (AIC) to assess goodness-of-fit and to determine which model was preferred. The lower values of these indices indicated a better model fit and it was observed that HeLD-14 models were better model fit than HeLD-29 models.

The convergent and discriminant validity, internal consistency and squared correlation between factors for HeLD-29 and HeLD-14 are demonstrated in Table 3.

Estimates of $\geq 0.50$ for AVE, and $\geq 0.70$ for $C R$ were demonstrated across all factors for both HeLD-29 and HeLD-14, indicating acceptable convergent validity for both forms. Discriminant validity was also demonstrated for both long and short-forms of the HeLD, given that the $A V E_{\mathrm{i}}$ and $A V E_{\mathrm{j}}$ were greater than the square of the correlation $\left(\rho_{\mathrm{ij}}{ }^{2}\right)$ between the factors $i$ and $j$ for both instruments. Internal consistency was adequate for the seven factors for both long- (HeLD-29) and short-form (HeLD-14) versions, with Cronbach standardized alpha being $\geq 0.70$ for both forms.

Table 4 presents the association between oral health literacy (HeLD-14 and sub-scales) and social demographic characteristics, general and oral health, oral health-related behaviors and GOHAI scores.

Table 2. Goodness of Fit Indices of Confirmatory Factor Analysis for HeLD-29 and HeLD- 14.

\begin{tabular}{|c|c|c|c|c|c|c|c|c|c|}
\hline Samples & $\lambda$ & $x^{2}$ & $d f$ & GFI & $\mathrm{CFI}$ & NFI & RMSEA & SRMR & $\mathrm{AIC}$ \\
\hline \multicolumn{10}{|c|}{ Data I $(n=267)$} \\
\hline HeLD-29 & $0.41-0.97$ & 1528.59 & 356 & 0.72 & 0.84 & 0.81 & 0.12 & 0.07 & 1686.59 \\
\hline HeLD-14 & $0.72-0.98$ & 99.53 & 56 & 0.95 & 0.98 & 0.97 & 0.05 & 0.03 & 197.53 \\
\hline \multicolumn{10}{|c|}{ Data II $(n=268)$} \\
\hline HeLD-29 & $0.41-0.99$ & 1534.33 & 356 & 0.72 & 0.84 & 0.81 & 0.13 & 0.07 & 1692.33 \\
\hline HeLD-14 & $0.72--0.98$ & 128.33 & 56 & 0.94 & 0.97 & 0.95 & 0.05 & 0.03 & 226.33 \\
\hline
\end{tabular}

$\lambda$ : factor weights range (min-max); CFI: comparative fit index; GFI: goodness of fit; NFI: Bentler-Bonett Normed fit index; RMSEA: root mean square error of approximation; AIC: Akaike Information Criterion. 


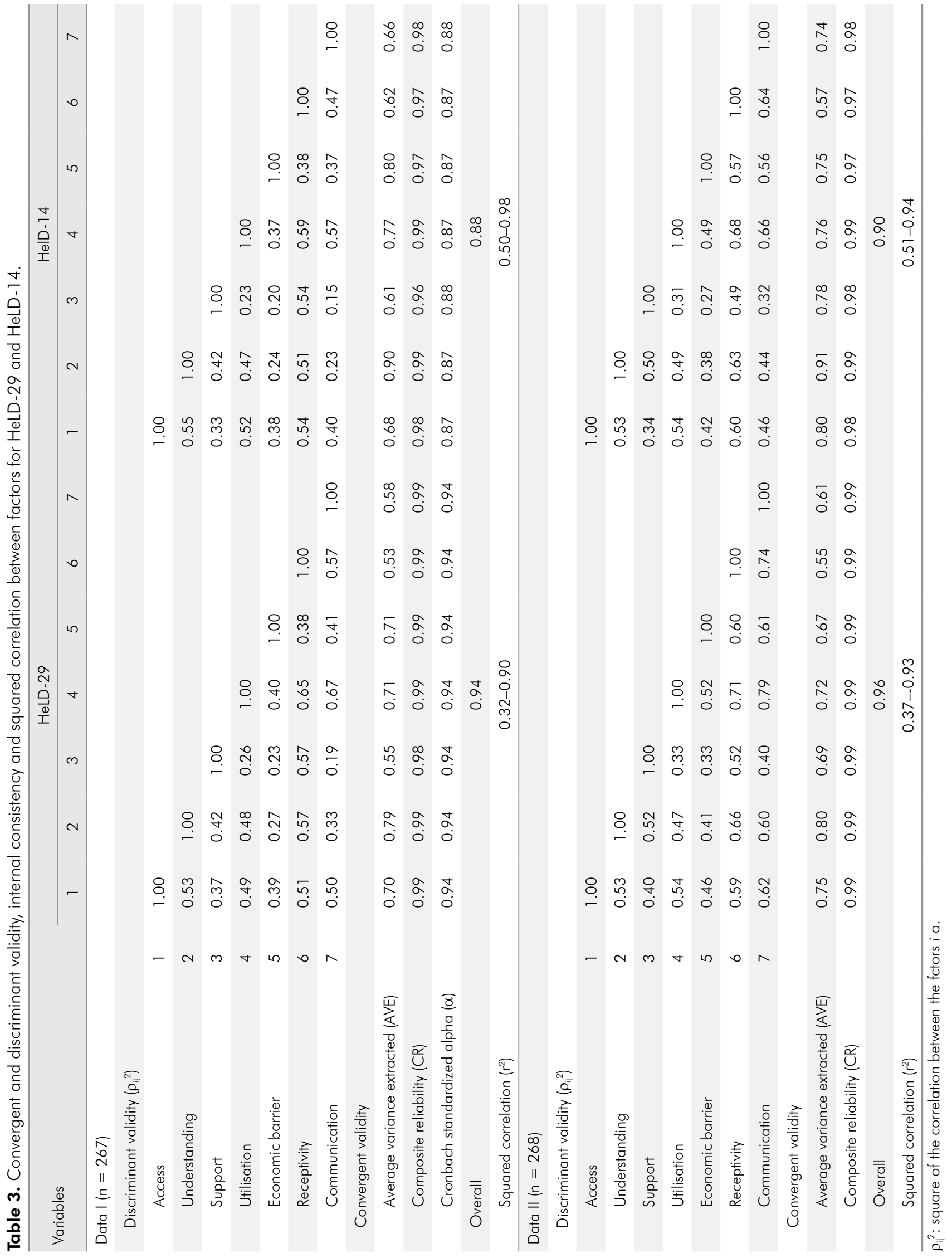




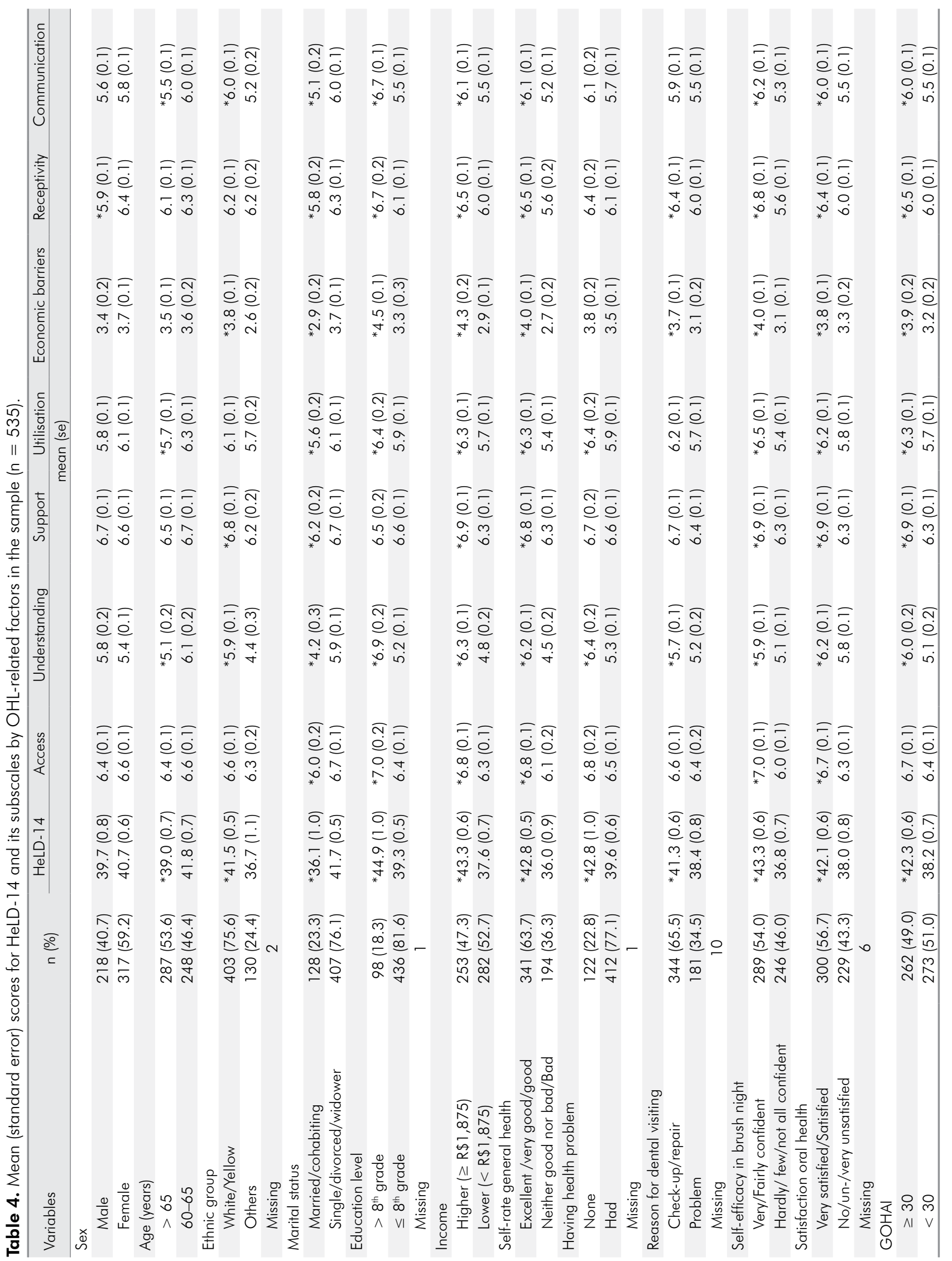


Higher scores were observed for either the total HeLD-14 and/or individual components of HeLD-14 related to sociodemographic variables and diverse general and oral health-related outcomes. The lowest mean scores for HeLD-14 was 36 in people with less than good self-ratings of general health.

The second-order models were developed only for the short-form version (HeLD-14), due to a better and more parsimonious fit to the data. It was observed that in data I: $p$-value $<0.0001$, SRMR $=0.07$, RESEA $=0.09$, $\mathrm{AIC}=1081.46, \mathrm{CFI}=0.92, \mathrm{NFI}=0.92, \mathrm{GFI}=0.90, \mathrm{DF}=70$, $\mathrm{X} 2=1011.47$. In relation to the data II: $\mathrm{p}$-value < 0.0001, $\mathrm{SRMR}=0.06, \mathrm{RESEA}=0.08, \mathrm{AIC}=891.57, \mathrm{CFI}=0.95$, $\mathrm{NFI}=0.94, \mathrm{GFI}=0.92, \mathrm{DF}=70, \mathrm{X} 2=821.57$ (Figure).

\section{Discussion}

The present study demonstrated that the short-form version of HeLD with 14 items demonstrated good psychometric properties for use with Brazilian older people to evaluate their OHL levels. To the best of our knowledge, this is the first study that has validated HeLD in populations in a language other than English and Indonesian ${ }^{10,11,12,14,15}$ and in older adults, contributing to providing health professionals and researchers with a valid and reliable tool to measure broad aspects of the OHL construct in this population, making it possible to perform future international comparisons between these findings.

Convergent and discriminant validity analyses demonstrated that the minimum estimates required for acceptable results were found for both forms of HeLD in the present study, as in the study of Ju et al. ${ }^{12}$ with Australian adults. In addition, the Cronbach's alpha coefficient demonstrated that the Brazilian version of HeLD had good internal consistency, such as that obtained in the validation studies with adult and Indigenous Australian, and with Indonesian undergraduates. ${ }^{10,11,12,14,15}$ This fact indicated that the instrument maintained its good properties in different languages, cultures and age groups. Although the reliability Cronbach's alpha value for HeLD-29 (0.94) was higher than HeLD-14 (0.89), both of them were more than 0.7 , which can be considerate acceptable.

We compared data I (AIC value for HeLD-14 model was 197.53) and confirmed that AIC values were less than HeLD-29 (1686.59). Therefore, HeLD -14 model reached better fit model in data I. The same was observed in relation to data II, that is, AIC value for HeLD-14 model was 226.33, less than 1692 for HeLD-29. This fact was also observed in a large sample of an Australian adult population. ${ }^{12}$ Similar findings was found with other shorter OHL instrument ${ }^{7,8,39}$ which demonstrated that smaller and more parsimonious set of variables (least number of items that still fits the conceptual framework) could score better psychometrically, because there is less noise from unwanted items. Although the short instrument cannot contain all oral health care items, it adequately captures the majority of constructs of long form. In addition, the short instrument makes it less prone to participant burden and easier to apply in health care and research settings. The scientific literature also shows evidence of several other instruments in short versions that have better psychometric properties than the long versions, proving that our results are not uncommon findings in the scientific literature. ${ }^{40,41,42,43,44}$

The mean scores of both versions of HeLD in the present study were lower than those found by Ju et al. ${ }^{12}$ with Australian adults, indicating lower levels of OHL in Brazilian older adult population. International evidence corroborates this trend between older age and low levels of general health literacy, ${ }^{22} \mathrm{a}$ fact that poses challenges to older adults to take care of their general and oral health, and also navigate health systems. Two of the individual HeLD items that presented the lowest values in our sample (1.55 and 2.02) were related to economic barriers faced by elderly (questions F1 -13 "Are you able to pay to see a dentist?" and F3-15 ("Are you able to pay for medication to manage your dental or oral health?") highlighting how economic determinants could impact on older persons' ability to find and use health information and services to take care of their oral health.

The HeLD-14 instrument demonstrated statistically significant differences in scale scores between diverse OHL-related factors. The model diagnostic used for these tests was based on previous theoretical frameworks and evidence from literature about the variables that are associated with OHL. Our results 


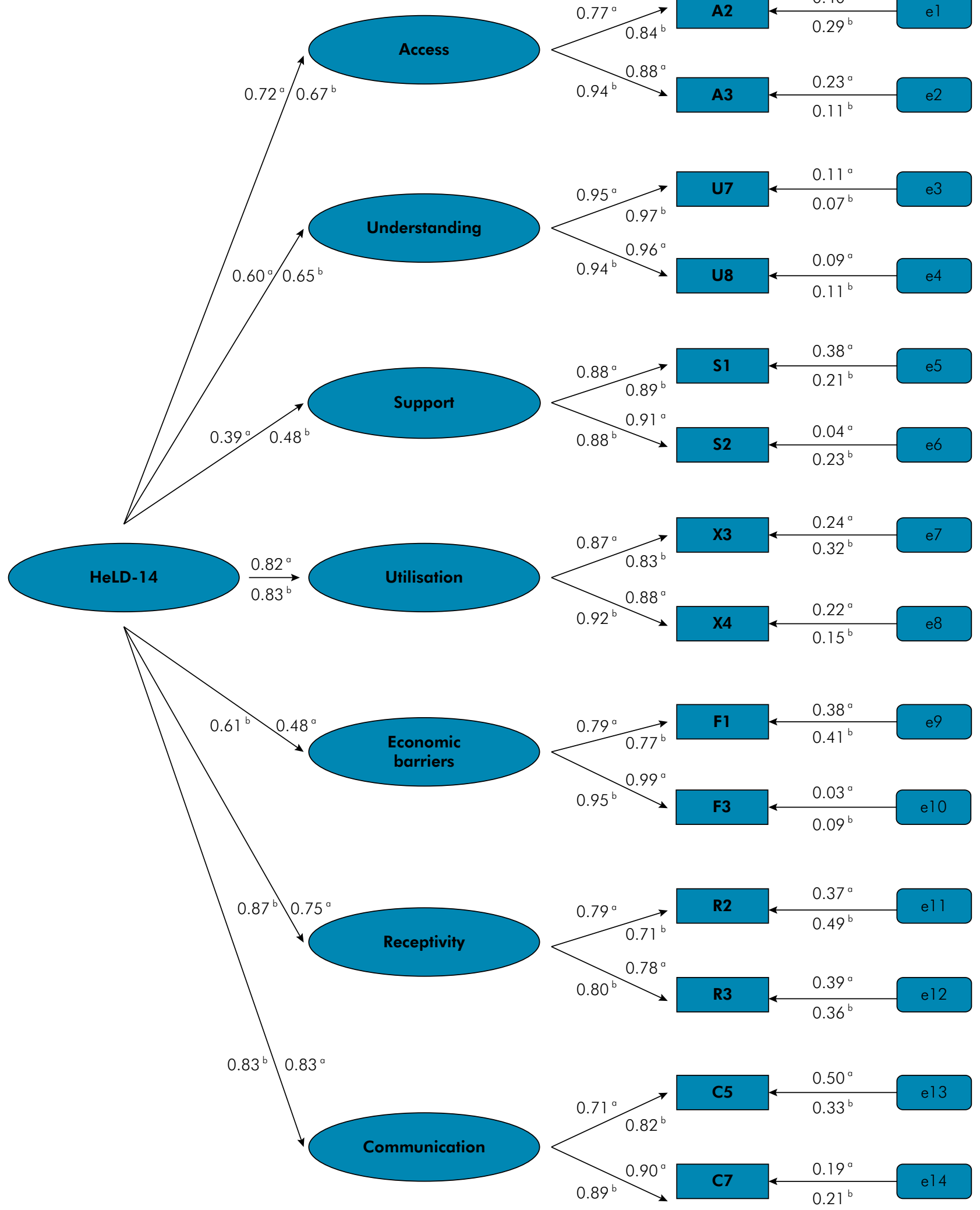

a: value from Data I; b: value from Data II; e: error, and linked number is error value; Other numbers are factor loadings.

Figure. Second-order models (' $a$ ' and ' $b$ ') for the short form oral health literacy instrument (HeLD-14). 
were similar to those found in the investigation with Australian adults, in which educational level of participants, reason for visiting the dentist, selfrated general and oral health factors were also associated with HeLD scale scores, ${ }^{12}$ reinforcing the evidence of the importance of these variables on $\mathrm{OHL}$ levels and the instrument's ability to distinguish between groups.

Although we used a large sample to measure the psychometric properties of HeLD in a Brazilian older population, the present study had some limitations. The participants of the present study lived near some type of dental public health service and this fact could have influenced their levels of oral health literacy when compared with the general population.
This could compromise the validity of our findings for older populations with different characteristics related to sociodemographic factors and quality of access to health services.

\section{Conclusions}

In conclusion, the Brazilian version of the short-form of Health Literacy Dental Scale (HeLD-14) was shown to be a reliable and valid instrument to measure broad aspects of OHL in an older Brazilian population.

\section{Acknowledgment}

Our greatest gratitude to the participants who contribute to this study.

\section{References}

1. Berkman ND, Sheridan SL, Donahue KE, Halpern DJ, Crotty K. Low health literacy and health outcomes: an updated systematic review. Ann Intern Med. 2011 Jul;155(2):97-107. https://doi.org/10.7326/0003-4819-155-2-201107190-00005

2. Kickbusch I, Pelikan JM, Apfel F, Tsouros A. Health literacy: the solid facts. Copenhagen: World Health Organization; 2013.

3. Nutbeam D. Health literacy as a public health goal: a challenge for contemporary health education and communication strategies into the 21st century. Health Promot Int. 2000;15(3):259-67. https://doi.org/10.1093/heapro/15.3.259

4. Lee JY, Rozier RG, Lee SY, Bender D, Ruiz RE. Development of a word recognition instrument to test health literacy in dentistry: the REALD-30: a brief communication. J Public Health Dent. 2007;67(2):94-8. https://doi.org/10.1111/j.1752-7325.2007.00021.x

5. Firmino RT, Martins CC, Faria LD, Martins Paiva S, Granville-Garcia AF, Fraiz FC, et al. Association of oral health literacy with oral health behaviors, perception, knowledge, and dental treatment related outcomes: a systematic review and meta-analysis. J Public Health Dent. 2018 Jun;78(3):231-45. https://doi.org/10.1111/iphd.12266

6. Junkes MC, Fraiz FC, Sardenberg F, Lee JY, Paiva SM, Ferreira FM. Validity and reliability of the Brazilian version of the rapid estimate of adult literacy in dentistry- BREALD-30. PLoS One. 2015 Jul;10(7):e0131600. https://doi.org/10.1371/journal.pone.0131600

7. Cruvinel AF, Méndez DA, Oliveira JG, Gutierres E, Lotto M, Machado MA, et al. The Brazilian version of the 20-item rapid estimate of adult literacy in medicine and dentistry. PeerJ. 2017 Aug;5:e3744. https://doi.org/10.7717/peeri.3744

8. Bado FM, Rebustini F, Jamieson L, Cortellazzi KL, Mialhe FL. Evaluation of the psychometric properties of the Brazilian version of the Oral Health Literacy Assessment in Spanish and development of a shortened form of the instrument. PLoS One. 2018 Nov;13(11):e0207989. https://doi.org/10.1371/journal.pone.0207989

9. Crozier S. House passes resolutions on oralheralth literacy. ADA News, 2006 Nov;37(21):18.

10. Jones K, Parker E, Mills H, Brennan D, Jamieson LM. Development and psychometric validation of a Health Literacy in Dentistry scale (HeLD). Community Dent Health. 2014 Mar;31(1):37-43. https://doi.org/10.1922/CDH_3269Jones07

11. Jones K, Brennan D, Parker E, Jamieson L. Development of a short-form Health Literacy Dental Scale (HeLD-14). Community Dent Oral Epidemiol. 2015 Apr;43(2):143-51. https://doi.org/10.1111/cdoe.12133

12. Ju X, Brennan DS, Parker E, Chrisopoulos S, Jamieson L. Confirmatory factor analysis of the health literacy in dentistry scale (HeLD) in the Australian population. Community Dent Health. 2018 Aug;35(3):140-7.

13. Henderson E, Dalawari P, Fitzgerald J, Hinyard L. Literacy and dental visitation in an inner-city emergency department population. Int J Environ Res Public Health. 2018 Aug;15(8):E1748. https://doi.org/10.3390/ijerph15081748

14. Rahardjo A, Wachid MN, Adiatman M, Wimardhani YS, Maharani DA. Health literacy in dentistry among undergraduate students in Indonesia. Asian J Epidemiol. 2016;9(1):24-9. https://doi.org/10.3923/aje.2016.24.29

15. Rahardjo A, Adinda S, Nasia AA, Adiatman M, Setiawati F, Wimardhani YS, et al. Oral health literacy in Indonsian adolescent. J Int Dent Med Res. 2015;8(3):123-7.

16. World Health Organization - WHO. World report on ageing and health 2015. Geneva: World Health Organization; 2015. 
17. Kossioni AE, Hajto-Bryk J, Maggi S, McKenna G, Petrovic M, Roller-Wirnsberger RE, et al. An expert opinion from the European College of Gerodontology and the European Geriatric Medicine Society: European policy recommendations on oral health in older adults. J Am Geriatr Soc. 2018 Mar;66(3):609-13. https://doi.org/10.1111/igs.15191

18. Murray Thomson W. Epidemiology of oral health conditions in older people. Gerodontology. 2014 Feb;31 Suppl 1:9-16. https://doi.org/10.1111/ger.12085

19. Ramsay SE, Whincup PH, Watt RG, Tsakos G, Papacosta AO, Lennon LT, et al. Burden of poor oral health in older age: findings from a population-based study of older British men. BMJ Open. 2015 Dec;5(12):e009476. https://doi.org/10.1136/bmjopen-2015-009476

20. Petersen PE, Ogawa H. Promoting Oral health and quality of life of older people: the need for public health action. Oral Health Prev Dent. 2018;16(2):113-24.

21. Brasil. SB Brasil 2010: Pesquisa nacional de saúde bucal: resultados principais. Brasília: Ministério da Saúde 2012.

22. Chesser AK, Keene Woods N, Smothers K, Rogers N. Health literacy and older adults: a systematic review. Gerontol Geriatr Med. 2016 Mar;2:2333721416630492. https://doi.org/10.1177/2333721416630492

23. Zamora H, Clingerman EM. Health literacy among older adults: a systematic literature review. J Gerontol Nurs. 2011 Oct;37(10):41-51.

24. Ueno M, Takeuchi S, Oshiro A, Kawaguchi Y. Relationship between oral health literacy and oral health behaviors and clinical status in Japanese adults. J Dent Sci. 2013;8(2):170-6. https://doi.org/10.1016/i.jds.2012.09.012

25. Rudd R, Horowitz AM. The role of health literacy in achieving oral health for elders. J Dent Educ. 2005 Sep;69(9):1018-21.

26. Chowdary MS, Sudhir KM, Reddy VC, Kumar K, Srinivasulu G. Oral health literacy and its impact on oral health status among institutionalised elderly population. IOSR J Dent Med Sci. 2015 Aug;14(8):96-104. https://doi.org/10.9790/0853-148296104

27. Guillemin F, Bombardier C, Beaton D. Cross-cultural adaptation of health-related quality of life measures: literature review and proposed guidelines. J Clin Epidemiol. 1993 Dec;46(12):1417-32. https://doi.org/10.1016/0895-4356(93)90142-N

28. Sousa VD, Roijanasrirat W. Translation, adaptation and validation of instruments or scales for use in cross-cultural health care research: a clear and user-friendly guideline. J Eval Clin Pract. 2011 Apr;17(2):268-74. https://doi.org/10.1111/j.1365-2753.2010.01434.x

29. Hair JF, Black WC, Babin BJ, Anderson RE. Multivariate data analysis. 7th ed. Harlow: Pearson Education; 2014.

30. Bado FM, Rebustini F, Azzi RG, Ferreira LC, Souza GA, Jamieson L, et al. Cross-cultural adaptation and validation of the self-efficacy scale to brush teeth at night. Cien Saude Colet 2019. https://orcid.org/0000-0002-7974-5456

31. Souza RF, Terada AS, Vecchia MP, Regis RR, Zanini AP, Compagnoni MA. Validation of the Brazilian versions of two inventories for measuring oral health-related quality of life of edentulous subjects. Gerodontology. 2012 Jun;29(2):e88-95. https://doi.org/10.1111/j.1741-2358.2010.00417.x

32. Atchison KA, Dolan TA. Development of the Geriatric Oral Health Assessment Index. J Dent Educ. 1990 Nov;54(11):680-7.

33. Kallner A. Laboratory statistics: methods in chemistry and health sciences. 2nd ed. Amsterdan: Elsevier; 2018.

34. George D, Mallery P. IBM SPSS Statistics 23 Step by Step A Simple Guide and Reference. 14th ed. New York: Routledge; 2016.

35. Curran PJ, West SG, Finch FJ. The robustness of test statistics to nonnormality and specification error in confirmatory factor analysis. Psychol Methods. 1996;1(1):16-29. https://doi.org/10.1037/1082-989X.1.1.16

36. Byrne BM. Structural equation modelling with EQS: Basic concepts, applications, and programming. 2nd ed. Mahwah: Erlbaum; 2006.

37. Hu L, Bentler PM. Cutoff criteria for fit indexes in covariance structure analysis: conventional criteria versus new alternatives. Struct Equ Modeling. 1999;6(1):1-37. https://doi.org/10.1080/10705519909540118

38. Fomell C, Larcker DF. Evaluating structural equation models with unobservable variables and measurement error. J Mark Res. 1981;18(1):39-50. https://doi.org/10.1177/002224378101800104

39. Stucky BD, Lee JY, Lee SY, Rozier RG. Development of the two-stage rapid estimate of adult literacy in dentistry. Community Dent Oral Epidemiol. 2011 Oct;39(5):474-80. https://doi.org/10.1111/j.1600-0528.2011.00619.x

40. Zucoloto ML, Maroco J, Campos JA. Psychometric Properties of the Oral Health Impact Profile and New Methodological Approach. J Dent Res. 2014 Jul;93(7):645-50. https://doi.org/10.1177/0022034514533798

41. Lee EH, Lee YW, Lee KW, Kim YS, Nam MS. Measurement of diabetes-related emotional distress using the Problem Areas in Diabetes scale: psychometric evaluations show that the short form is better than the full form. Health Qual Life Outcomes. 2014 Oct;12(1):142. https://doi.org/10.1186/s12955-014-0142-z

42. Axfors C, Sylvén S, Skalkidou A, Ramklint M. Psychometric properties of the attachment style questionnaire in Swedish pregnant women: short and full versions. J Reprod Infant Psychol. 2017 Nov;35(5):450-61. https://doi.org/10.1080/02646838.2017.1342786

43. Pedersen G, Selsbakk JM, Theresa W, Sigmund K. Testing different versions of the Affective Neuroscience Personality Scales in a clinical sample. PLoS One. 2014 Oct 7;9(10):e109394. https://doi.org/10.1371/journal.pone.0109394

44. Moret L, Nguyen JM, Pillet N, Falissard B, Lombrail P, Gasquet I. Improvement of psychometric properties of a scale measuring inpatient satisfaction with care: a better response rate and a reduction of the ceiling effect. BMC Health Serv Res. 2007 Dec;7(1):197. https://doi.org/10.1186/1472-6963-7-197 